\title{
Hybrid Synchronization of Hyperchaotic Lorenz and Hyperchaotic Chen Systems via Active Control
}

\author{
${ }^{1} \mathrm{~V}$. Sundarapandian and ${ }^{2} \mathrm{R}$. Karthikeyan \\ ${ }^{1}$ Research and Development Centre, Vel Tech Dr. RR \& Dr. SR Technical University, \\ Avadi, 600062 Chennai, India \\ ${ }^{2}$ School of Electronics and Electrical Engineering, Singhania University, \\ District Jhunjhunu, 333515 Rajasthan, India
}

\begin{abstract}
This study investigates the hybrid synchronization of Hyperchaotic Lorenz and Chen Systems via adaptive control. Explicitly, researchers derive new results for the hybrid chaos synchronization of identical Hyperchaotic Lorenz Systems, identical Hyperchaotic Chen Systems and non-identical Hyperchaotic Lorenz and Chen Systems. In this study, Researchers assume that the parameters of both master and slave systems are unknown and we devise adaptive hybrid synchronization schemes using the estimates of parameters for both Master and Slave Systems. The adaptive hybrid synchronization results derived in this study are established using Lyapunov Stability Theory. Since, the Lyapunov exponents are not required for these calculations, the proposed Adaptive Control Method is very effective and convenient to achieve hybrid synchronization of identical and non-identical Hyperchaotic Lorenz and Chen Systems. Numerical simulations are shown to demonstrate the effectiveness of the proposed adaptive hybrid synchronization schemes for the hyperchaotic systems addressed in this study.
\end{abstract}

Key words: Adaptive control, hyperchaos, hybrid synchronization, Hyperchaotic Lorenz System, Hyperchaotic Chen System, India

\section{INTRODUCTION}

Chaotic Systems are non-linear dynamical systems that are highly sensitive to initial conditions. This sensitivity is popularly known as the butterfly effect (Alligood et al., 1997). The chaos phenomenon was first observed in weather models by Lorenz (1963). Hyperchaotic System is usually defined as a Chaotic System having more than one positive Lyapunov exponent. The hyperchaos phenomenon was first observed by Rossler (1979). A Hyperchaotic System has the characteristics of high capacity, high security and high efficiency. Thus, it has the potential of broad applications in non-linear circuits, secure communications, lasers, neural networks, biological systems and so on.

Synchronization of Chaotic Systems is a phenomenon that may occur when two or more chaotic oscillators are coupled or when a chaotic oscillator drives another chaotic oscillator. Because of the butterfly effect which causes the exponential divergence of the trajectories of two identical Chaotic Systems started with nearly the same initial conditions, synchronizing two
Chaotic Systems is seemingly a very challenging research problem. In most of the chaos synchronization approaches, the master-slave or drive-response formalism is used. If a particular Chaotic System is called a master or drive system and another Chaotic System is called a slave or response system then the idea of chaos synchronization is to use the output of the master system to control the slave system so that the output of the slave system tracks the output of the master system asymptotically.

Chaos is an interesting non-linear phenomenon and it has been intensively and extensively studied in the last three decades. Chaos Theory has wide applications in several fields such as Physical Systems (Lakshmanan and Murali, 1996), Chemical Systems (Han et al., 1995), Ecological Systems (Blasius et al., 1999) and secure communications, etc. (Cuomo et al., 1993; Kocarev and Parlitz, 1995).

In most of the chaos synchronization approaches, the master-slave or drive-response formalism is used. If a particular Chaotic System is called the master or drive system and another Chaotic System is called the slave or response system then the idea of synchronization is to

Corresponding Author: V. Sundarapandian, Research and Development Centre, Vel Tech Dr. RR \& Dr. SR Technical University, Avadi, 600062 Chennai, India 
use the output of the master system to control the slave system so that the states of the slave system track the states of the master system asymptotically. Since, the seminal research by Pecora and Carroll (1990) on complete synchronization of Chaotic Systems, there has been significant interest paid in the chaos literature on the synchronization of Chaotic and Hyperchaotic Systems (Pecora and Carroll, 1990; Ott et al., 1990; Yang and Chua, 1999; Park and Kwon, 2003; Hua and Guan, 2003; Ho and Hung, 2002; Yassen, 2003, 2005; Tian et al., 2007; Sundarapandian, 2011a-f; Chen and Lu, 2002; Jia and Tang, 2009; Mascolo and Grassi, 1999; Tan et al., 2003; Zhang et al., 2005; Utkin, 1977; Slotine and Sastry, 1983; Sundarapandian and Sivaperumal, $2011 \mathrm{a}$, b; Ge and Chen, 2004; Wang and Guan, 2006; Zhang and Zhu, 2008; Chiang et al., 2008; Jia, 2007; Yan and Li, 2006; Li et al., 2007; Sarasu and Sundarapandian, 2011).

In the last 2 decades, several approaches have been developed for chaos synchronization such as the OGY Method (Ott et al., 1990), Sampled-data Feedback Synchronization Method (Yang and Chua, 1999), the Time-delay Feedback Method (Park and Kwon, 2003; Hua and Guan, 2003), the Active Control Method (Ho and Hung, 2002; Yassen, 2005; Tian et al., 2007; Sundarapandian, 2011 a, b), the Adaptive Control Method (Yassen, 2003; Chen and Lu, 2002; Jia and Tang, 2009; Sundarapandian, 2011c, d), the Backstepping Method (Mascolo and Grassi, 1999; Tan et al., 2003; Zhang et al., 2005), the Sliding Mode Control Method (Utkin, 1977; Slotine and Sastry, 1983; Sundarapandian and Sivaperumal, 2011a, b) and others.

So far, various synchronization methods have been developed such as the complete synchronization (Pecora and Carroll, 1990), the phase synchronization (Ge and Chen, 2004), the generalized synchronization (Wang and Guan, 2006), the anti-synchronization (Zhang and Zhu, 2008; Chiang et al., 2008; Sundarapandian, 2011g; Sundarapandian and Sivaperumal, 2011b), the projective synchronization (Jia, 2007) and the generalized projective synchronization (Yan and Li, 2006; Li et al., 2007; Sarasu and Sundarapandian, 2011). Complete Synchronization (CS) is characterized by the equality of state variables evolving in time while the Anti-Synchronization (AS) is characterized by the disappearance of the sum of relevant state variables evolving in time.

Projective Synchronization (PS) is characterized by the fact the master and slave systems could be synchronized up to a scaling factor whereas in Generalized Projective Synchronization (GPS), the responses of the synchronized dynamical states synchronize up to a constant scaling matrix $\alpha$. It is easy to see that the complete synchronization and the anti-synchronization are the special cases of the generalized projective synchronization where the scaling matrix $\alpha=1$ and $\alpha=-1$, respectively.

In hybrid synchronization of Chaotic Systems (Sundarapandian, 2011h), one part of the systems (for instance, the odd-numbered states) is completely synchronized while the other part (for instance, the even numbered states) is anti-synchronized so that Complete Synchronization (CS) and Anti-Synchronization (AS) co-exist in the Master-Slave Chaotic Systems. The co-existence of CS and AS is very useful in secure communication and chaotic encryption schemes.

In this study, researchers deploy the Adaptive Control Method to derive new results for the hybrid synchronization of identical Hyperchaotic Lorenz Systems (Gao et al., 2007), identical Hyperchaotic Chen Systems (Li-Xin et al., 2010) and non-identical Hyperchaotic Lorenz and Chen Systems. The adaptive synchronization results for the hybrid synchronization of Hyperchaotic Lorenz and Chen Systems are established by the Lyapunov Stability Theory (Hahn, 1967).

Systems description: The Hyperchaotic Lorenz System is a new hyperchaotic system derived from the Lorenz System by Gao et al. (2007). The Hyperchaotic Lorenz System is described by the 4D dynamics:

$$
\begin{aligned}
& \dot{\mathrm{x}}_{1}=\sigma\left(\mathrm{x}_{2}-\mathrm{x}_{1}\right) \\
& \dot{\mathrm{x}}_{2}=\rho \mathrm{x}_{1}-\mathrm{x}_{2}-\mathrm{x}_{4}-\mathrm{x}_{1} \mathrm{x}_{3} \\
& \dot{\mathrm{x}}_{3}=\mathrm{x}_{1} \mathrm{x}_{2}-\beta \mathrm{x}_{3} \\
& \dot{\mathrm{x}}_{4}=\operatorname{rx}_{2} \mathrm{x}_{3}
\end{aligned}
$$

Where $x_{i}(i=1,2,3,4)$ are the states and $\sigma, \beta, \rho, \mathrm{r}$ are positive, constant parameters of the system. The system (1) is hyperchaotic when the parameter values are chosen as:

$$
\sigma=10, \beta=8 / 3, \rho=28 \text { and } r=0.1
$$

Figure 1 shows the phase portrait of the Hyperchaotic Lorenz System (1). The Hyperchaotic Chen System is a new hyperchaotic system derived from the Chen System by Li-Xin et al. (2010). The Hyperchaotic Chen System is described by the 4D dynamics:

$$
\begin{aligned}
& \dot{\mathrm{x}}_{1}=\mathrm{a}\left(\mathrm{x}_{2}-\mathrm{x}_{1}\right) \\
& \dot{\mathrm{x}}_{2}=4 \mathrm{x}_{1}-10 \mathrm{x}_{1} \mathrm{x}_{3}+\mathrm{cx}_{2}+4 \mathrm{x}_{4} \\
& \dot{\mathrm{x}}_{3}=\mathrm{x}_{2}^{2}-\mathrm{bx}_{3} \\
& \dot{\mathrm{x}}_{4}=-\mathrm{dx}_{1}
\end{aligned}
$$



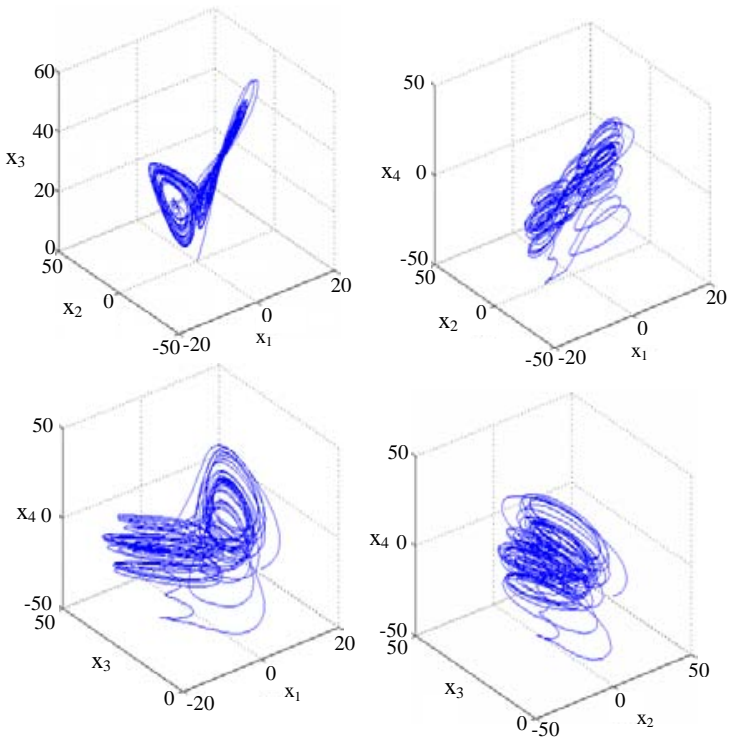

Fig. 1: Phase portrait of the Hyperchaotic Lorenz System
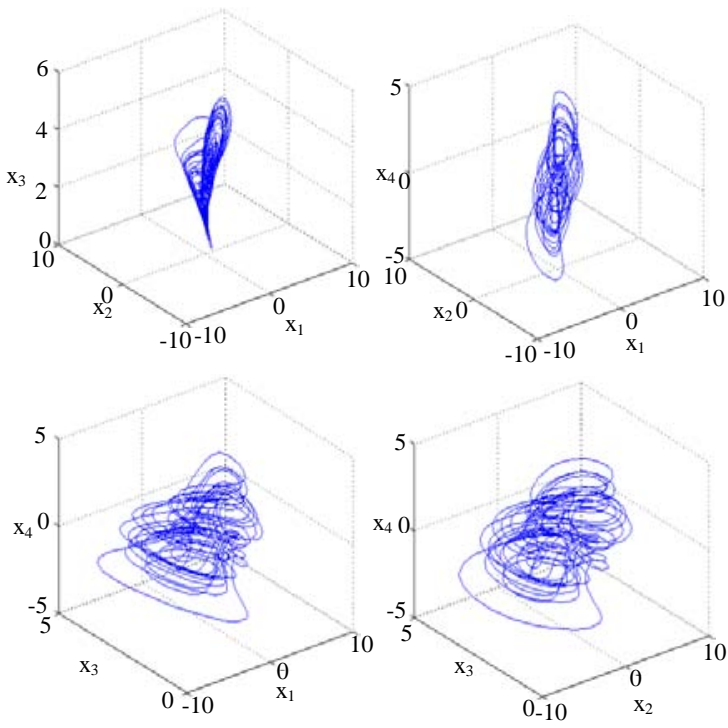

Fig. 2: Phase portrait of the Hyperchaotic Chen System

Where, $x_{i}(i=1,2,3,4)$ are the states and a-d are positive, constant parameters of the system. The system (2) is hyperchaotic when the parameter values are taken as:

$$
\mathrm{a}=35, \mathrm{~b}=3, \mathrm{c}=21 \text { and } \mathrm{d}=2
$$

Figure 2 shows the phase portrait of the Hyperchaotic Chen System (2).

\section{ADAPTIVE HYBRID SYNCHRONIZATION OF IDENTICAL HYPERCHAOTIC LORENZ SYSTEMS}

Theoretical results: In this research, researchers deploy the Adaptive Control Method to derive new results for the hybrid synchronization of identical Hyperchaotic Lorenz Systems (Gao et al., 2007). Thus, the master system is described by the Hyperchaotic Lorenz dynamics:

$$
\begin{aligned}
& \dot{\mathrm{x}}_{1}=\sigma\left(\mathrm{x}_{2}-\mathrm{x}_{1}\right) \\
& \dot{\mathrm{x}}_{2}=\rho \mathrm{x}_{1}-\mathrm{x}_{2}-\mathrm{x}_{4}-\mathrm{x}_{1} \mathrm{x}_{3} \\
& \dot{\mathrm{x}}_{3}=\mathrm{x}_{1} \mathrm{x}_{2}-\beta \mathrm{x}_{3} \\
& \dot{\mathrm{x}}_{4}=\operatorname{rx}_{2} \mathrm{x}_{3}
\end{aligned}
$$

Where $\mathrm{x}_{1}-\mathrm{x}_{4}$ are the states and $\alpha, \beta, \rho, \mathrm{r}$ are unknown parameters of the system. The slave system is described by the controlled Hyperchaotic Lorenz dynamics:

$$
\begin{aligned}
& \dot{\mathrm{y}}_{1}=\sigma\left(\mathrm{y}_{2}-\mathrm{y}_{1}\right)+\mathrm{u}_{1} \\
& \dot{\mathrm{y}}_{2}=\rho \mathrm{y}_{1}-\mathrm{y}_{2}-\mathrm{y}_{4}-\mathrm{y}_{1} \mathrm{y}_{3}+\mathrm{u}_{2} \\
& \dot{\mathrm{y}}_{3}=\mathrm{y}_{1} \mathrm{y}_{2}-\beta \mathrm{y}_{3}+\mathrm{u}_{3} \\
& \dot{\mathrm{y}}_{4}=\mathrm{ry}_{2} \mathrm{y}_{3}+\mathrm{u}_{4}
\end{aligned}
$$

Where $\mathrm{y}_{1}-\mathrm{y}_{4}$ are the states and $\mathrm{ur}_{\mathrm{r}} \mathrm{u}_{4}$ are the adaptive controllers to be designed. The hybrid synchronization error is defined as:

$$
\begin{array}{ll}
\mathrm{e}_{1}=\mathrm{y}_{1}-\mathrm{x}_{1}, & \mathrm{e}_{2}=\mathrm{y}_{2}+\mathrm{x}_{2} \\
\mathrm{e}_{3}=\mathrm{y}_{3}-\mathrm{x}_{3}, & \mathrm{e}_{4}=\mathrm{y}_{4}+\mathrm{x}_{4}
\end{array}
$$

A simple calculation gives the error dynamics as:

$$
\begin{aligned}
\dot{\mathrm{e}}_{1}=\sigma\left(\mathrm{e}_{2}-\mathrm{e}_{1}-2 \mathrm{x}_{2}\right)+\mathrm{u}_{1} & \\
\dot{\mathrm{e}}_{2}=\rho\left(\mathrm{e}_{1}+2 \mathrm{x}_{1}\right)-\mathrm{e}_{2}-\mathrm{e}_{4}- & \mathrm{y}_{1} \mathrm{y}_{3}-\mathrm{x}_{1} \mathrm{x}_{3}+\mathrm{u}_{2} \\
\dot{\mathrm{e}}_{3}= & -\beta \mathrm{e}_{3}+\mathrm{y}_{1} \mathrm{y}_{2}-\mathrm{x}_{1} \mathrm{x}_{2}+\mathrm{u}_{3} \\
\dot{\mathrm{e}}_{4}= & r\left(\mathrm{y}_{2} \mathrm{y}_{3}+\mathrm{x}_{2} \mathrm{x}_{3}\right)+\mathrm{u}_{4}
\end{aligned}
$$

Let us now define the adaptive functions $\mathrm{u}_{1}(\mathrm{t})-\mathrm{u}_{4}(\mathrm{t})$ as:

$$
\begin{aligned}
\mathrm{u}_{1}(\mathrm{t})= & -\hat{\mathrm{\sigma}}\left(\mathrm{e}_{2}-\mathrm{e}_{1}-2 \mathrm{x}_{2}\right)-\mathrm{k}_{1} \mathrm{e}_{1} \\
\mathrm{u}_{2}(\mathrm{t})= & -\hat{\rho}\left(\mathrm{e}_{1}+2 \mathrm{x}_{1}\right)+\mathrm{e}_{2}+\mathrm{e}_{4}+ \\
& \mathrm{y}_{1} \mathrm{y}_{3}+\mathrm{x}_{1} \mathrm{x}_{3}-\mathrm{k}_{2} \mathrm{e}_{2} \\
\mathrm{u}_{3}(\mathrm{t})= & \hat{\beta} \mathrm{e}_{3}-\mathrm{y}_{1} \mathrm{y}_{2}+\mathrm{x}_{1} \mathrm{x}_{2}-\mathrm{k}_{3} \mathrm{e}_{3} \\
\mathrm{u}_{4}(\mathrm{t})= & -\hat{\mathrm{r}}\left(\mathrm{y}_{2} \mathrm{y}_{3}+\mathrm{x}_{2} \mathrm{x}_{3}\right)-\mathrm{k}_{4} \mathrm{e}_{4}
\end{aligned}
$$

Where $\hat{\sigma}, \hat{\beta}, \hat{\rho}$ and $\hat{\mathrm{r}}$ are estimates of $\sigma, \beta, \rho$ and $\mathrm{r}$, respectively and $k_{i}(i=1,2,3,4)$ are positive constants. Substituting Eq. 7 into Eq. 6, the error dynamics simplifies to:

$$
\begin{aligned}
& \dot{\mathrm{e}}_{1}=(\sigma-\hat{\sigma})\left(\mathrm{e}_{2}-\mathrm{e}_{1}-2 \mathrm{x}\right)-\mathrm{k}_{1} \mathrm{e}_{1} \\
& \dot{\mathrm{e}}_{2}=(\rho-\hat{\rho})\left(\mathrm{e}_{1}+2 \mathrm{x}_{1}\right)-\mathrm{k}_{2} \mathrm{e}_{2} \\
& \dot{\mathrm{e}}_{3}=-(\beta-\hat{\beta}) \mathrm{e}_{3}-\mathrm{k}_{3} \mathrm{e}_{3} \\
& \dot{\mathrm{e}}_{4}=(\mathrm{r}-\hat{\mathrm{r}})\left(\mathrm{y}_{2} \mathrm{y}_{3}+\mathrm{x}_{2} \mathrm{x}_{3}\right)-\mathrm{k}_{4} \mathrm{e}_{4}
\end{aligned}
$$


Let us now define the parameter estimation error as:

$$
\begin{array}{ll}
\mathrm{e}_{\sigma}=\sigma-\hat{\sigma}, & \mathrm{e}_{\beta}=\beta-\hat{\beta} \\
\mathrm{e}_{\rho}=\rho-\hat{\rho}, & \mathrm{e}_{\mathrm{r}}=\mathrm{r}-\hat{\mathrm{r}}
\end{array}
$$

Substituting Eq. 9 into Eq. 8, researchers obtain the error dynamics as:

$$
\begin{aligned}
& \dot{\mathrm{e}}_{1}=\mathrm{e}_{\sigma}\left(\mathrm{e}_{2}-\mathrm{e}_{1}-2 \mathrm{x}_{1}\right)-\mathrm{k}_{1} \mathrm{e}_{1} \\
& \dot{\mathrm{e}}_{2}=\mathrm{e}_{\mathrm{\rho}}\left(\mathrm{e}_{1}+2 \mathrm{x}_{1}\right)-\mathrm{k}_{2} \mathrm{e}_{2} \\
& \dot{\mathrm{e}}_{3}=-\mathrm{e}_{\beta} \mathrm{e}_{3}-\mathrm{k}_{3} \mathrm{e}_{3} \\
& \dot{\mathrm{e}}_{4}=\mathrm{e}_{\mathrm{r}}\left(\mathrm{y}_{2} \mathrm{y}_{3}+\mathrm{x}_{2} \mathrm{x}_{3}\right)-\mathrm{k}_{4} \mathrm{e}_{4}
\end{aligned}
$$

For the derivation of the update law for adjusting the estimates of the parameters, the Lyapunov approach is used. Researchers consider the quadratic Lyapunov function defined by:

$$
\mathrm{V}=\frac{1}{2}\left(\mathrm{e}_{1}^{2}+\mathrm{e}_{2}^{2}+\mathrm{e}_{3}^{2}+\mathrm{e}_{4}^{2}+\mathrm{e}_{\sigma}^{2}+\mathrm{e}_{\beta}^{2}+\mathrm{e}_{\rho}^{2}+\mathrm{e}_{\mathrm{r}}^{2}\right)
$$

Which is a positive definite function on $R^{8}$. Researchers also note that:

$$
\dot{\mathrm{e}}_{\sigma}=-\dot{\hat{\sigma}}, \quad \dot{\mathrm{e}}_{\beta}=-\dot{\hat{\hat{\beta}}}, \quad \dot{\mathrm{e}}_{\rho}=-\dot{\hat{\rho}}, \dot{\mathrm{e}}_{\mathrm{r}}=-\dot{\hat{\mathrm{r}}}
$$

Differentiating Eq. 11 along the trajectories of Eq. 10 and noting Eq. 12, researchers find that:

$$
\begin{aligned}
\dot{\mathrm{V}}= & -\mathrm{k}_{1} \mathrm{e}_{1}^{2}-\mathrm{k}_{2} \mathrm{e}_{2}^{2}-\mathrm{k}_{3} \mathrm{e}_{3}^{2}-\mathrm{k}_{4} \mathrm{e}_{4}^{2}+ \\
& \mathrm{e}_{\sigma}\left[\mathrm{e}_{1}\left(\mathrm{e}_{2}-\mathrm{e}_{1}-2 \mathrm{x}_{2}\right)-\dot{\hat{\sigma}}\right]+ \\
& \mathrm{e}_{\beta}\left[-\mathrm{e}_{3}^{2}-\dot{\hat{\beta}}\right]+\mathrm{e}_{\rho}\left[\mathrm{e}_{2}\left(\mathrm{e}_{1}+2 \mathrm{x}_{1}\right)-\dot{\hat{\rho}}\right]+ \\
& \mathrm{e}_{\mathrm{r}}\left[\mathrm{e}_{4}\left(\mathrm{y}_{2} \mathrm{y}_{3}+\mathrm{x}_{2} \mathrm{x}_{3}\right)-\dot{\hat{\mathrm{r}}}\right]
\end{aligned}
$$

In view of Eq. 13, the estimated parameters are updated by the following law:

$$
\begin{aligned}
& \dot{\hat{\sigma}}=\mathrm{e}_{1}\left(\mathrm{e}_{2}-\mathrm{e}_{1}-2 \mathrm{x}_{2}\right)+\mathrm{k}_{5} \mathrm{e}_{\sigma} \\
& \dot{\hat{\beta}}=-\mathrm{e}_{3}^{2}+\mathrm{k}_{6} \mathrm{e}_{\beta} \\
& \dot{\hat{\rho}}=\mathrm{e}_{2}\left(\mathrm{e}_{1}+2 \mathrm{x}_{1}\right)+\mathrm{k}_{7} \mathrm{e}_{\rho} \\
& \dot{\hat{\mathrm{r}}}=\mathrm{e}_{4}\left(\mathrm{y}_{2} \mathrm{y}_{3}+\mathrm{x}_{2} \mathrm{x}_{3}\right)+\mathrm{k}_{8} \mathrm{e}_{\mathrm{r}}
\end{aligned}
$$

Where, $\mathrm{k}_{5}-\mathrm{k}_{8}$ are positive constants.
Theorem 1: The identical Hyperchaotic Lorenz Systems (3) and (4) with unknown parameters are globally and exponentially hybrid-synchronized by the adaptive control law (Eq. 7) where the update law for the parameter estimates $\sigma, \beta, \rho, \mathrm{r}$ is given by Eq. 14 and $\mathrm{k}_{\mathrm{i}}(\mathrm{i}=1,2, \ldots, 8)$ are positive constants. The errors for parameter estimates $\mathrm{e}_{\sigma}, \mathrm{e}_{\beta}, \mathrm{e}_{\rho}, \mathrm{e}_{\mathrm{r}}$ decay to zero exponentially as $\mathrm{t} \rightarrow \infty$.

Proof: This result is a simple consequence of the Lyapunov Stability Theory. Researchers know that $\mathrm{V}$ as defined in Eq. 11 is a positive definite function on $\mathrm{R}^{8}$. Substituting Eq. 14 into Eq. 13, researchers obtain:

$$
\begin{gathered}
\dot{\mathrm{V}}=- \\
-\mathrm{k}_{1} \mathrm{e}_{1}^{2}-\mathrm{k}_{2} \mathrm{e}_{2}^{2}-\mathrm{k}_{3} \mathrm{e}_{3}^{2}-\mathrm{k}_{4} \mathrm{e}_{4}^{2}- \\
\mathrm{k}_{5} \mathrm{e}_{\sigma}^{2}-\mathrm{k}_{6} \mathrm{e}_{\rho}^{2}-\mathrm{k}_{7} \mathrm{e}_{\beta}^{2}-\mathrm{k}_{8} \mathrm{e}_{\mathrm{r}}^{2}
\end{gathered}
$$

Which is a negative definite function on $\mathrm{R}^{8}$. Hence, by the Lyapunov Stability Theory (Hahn, 1967), it follows that $e_{i}(t) \rightarrow 0$ as $t \rightarrow \infty$ for $i=1,2,3,4$ and $e_{\sigma} \rightarrow 0, e_{\beta} \rightarrow 0, e_{p} \rightarrow 0$, $\mathrm{e}_{\mathrm{r}} \rightarrow 0$ as $\mathrm{t} \rightarrow \infty$, exponentially. This completes the proof.

Numerical results: For the numerical simulations, the 4th-order Runge-Kutta Method with time-step $\mathrm{h}=10^{-8}$ is used to solve the two systems of differential Eq. 3 and 4 with the adaptive non-linear controller (Eq. 7) and update law of estimates (Eq. 14). Researchers take $k_{i}=4$ for $\mathrm{i}=1,2, \ldots, 8$. The parameters of the Hyperchaotic Lorenz Systems are chosen so that the systems (3) and (4) are hyperchaotic, i.e.,

$$
\sigma=10, \beta=8 / 3, \rho=28 \text { and } \mathrm{r}=0.1
$$

The initial values of the parameter estimates are chosen as:

$$
\hat{\sigma}(0)=5, \hat{\beta}(0)=3, \hat{\rho}(0)=10 \text { and } \hat{r}(0)=6
$$

The initial values of the master system (3) are chosen as:

$$
x_{1}(0)=2, x_{2}(0)=-5, x_{3}(0)=6, x_{4}(0)=-12
$$

The initial values of the slave system (4) are chosen as:

$$
\mathrm{y}_{1}(0)=7, \mathrm{y}_{2}(0)=5, \mathrm{y}_{3}(0)=6, \mathrm{y}_{4}(0)=1
$$

Figure 3 shows the hybrid synchronization of the Hyperchaotic Lorenz Systems (3) and (4). Figure 4 shows the time-history of the hybrid synchronization errors. Figure 5 shows the time-history of the parameter estimates $\hat{\sigma}, \hat{\beta}, \hat{p}, \hat{r}$. Figure 6 shows the time-history of the parameter estimation errors $\mathrm{e}_{\sigma}, \mathrm{e}_{\beta}, \mathrm{e}_{\rho}, \mathrm{e}_{\mathrm{r}}$. 

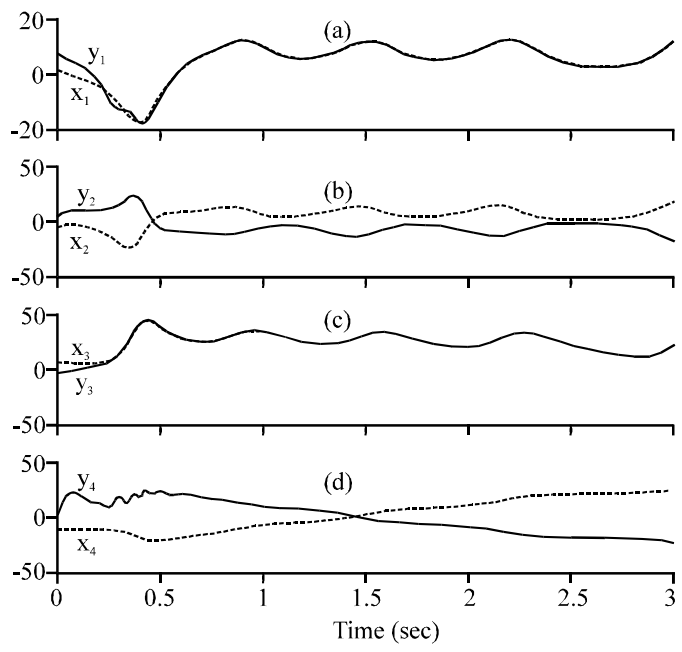

Fig. 3: a-d) Hybrid synchronization of the identical Hyperchaotic Lorenz Systems

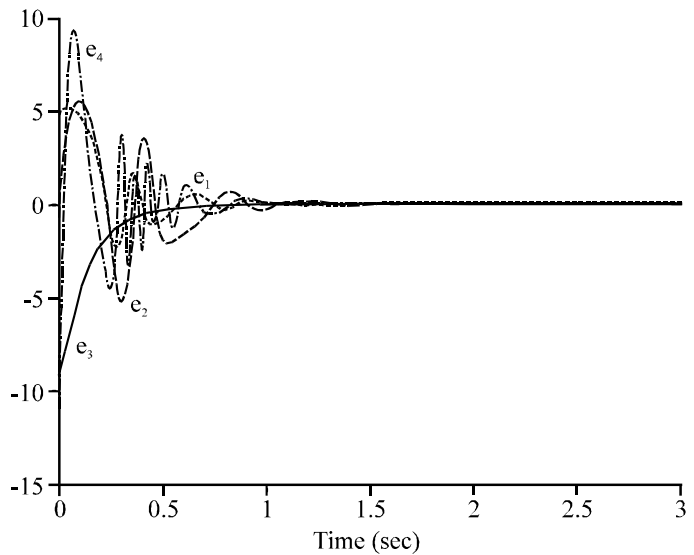

Fig. 4: Time history of the error states $e_{1}-e_{4}$

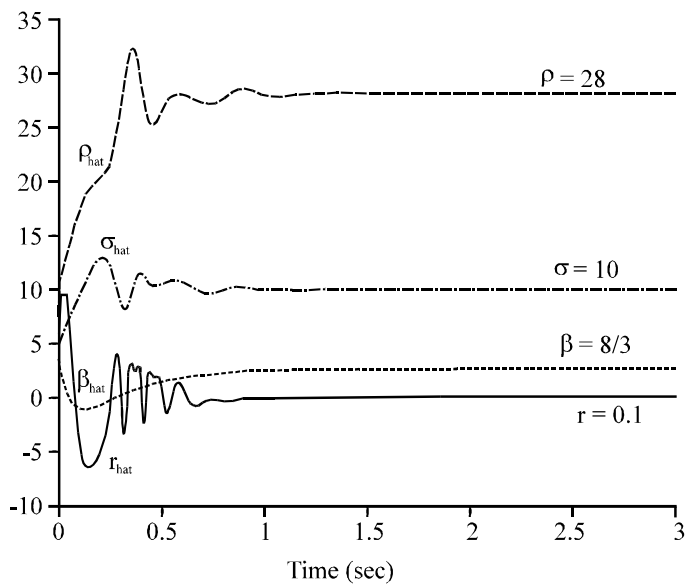

Fig. 5: Time history of the parameter estimates $\hat{\sigma}, \hat{\beta}, \hat{\rho}, \hat{r}$

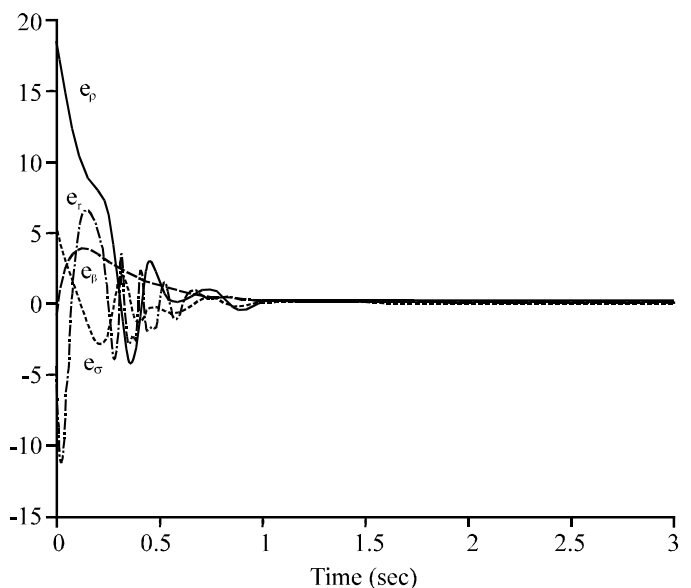

Fig. 6: Time history of the parameter estimation errors $\mathrm{e}_{\sigma}$, $\mathrm{e}_{\beta}, \mathrm{e}_{\rho}, \mathrm{e}_{\mathrm{r}}$

\section{ADAPTIVE HYBRD SYNCHRONIZATION OF IDENTICAL HYPERCHAOTIC CHEN SYSTEMS}

Theoretical results: In this research, researchers deploy the Adaptive Control Method to derive new results for the hybrid synchronization of identical Hyperchaotic Chen System (Li-Xin et al., 2010). Thus, the master system is described by the Hyperchaotic Chen dynamics:

$$
\begin{aligned}
& \dot{\mathrm{x}}_{1}=\mathrm{a}\left(\mathrm{x}_{2}-\mathrm{x}_{1}\right), \dot{\mathrm{x}}_{2}=4 \mathrm{x}_{1}-10 \mathrm{x}_{1} \mathrm{x}_{3}+\mathrm{cx}_{2}+4 \mathrm{x}_{4} \\
& \dot{\mathrm{x}}_{3}=\mathrm{x}_{2}^{2}-\mathrm{bx}_{3}, \quad \dot{\mathrm{x}}_{4}=-\mathrm{dx}_{1}
\end{aligned}
$$

Where $\mathrm{x}_{1}-\mathrm{x}_{4}$ are the states and a-d are unknown parameters of the system. The slave system is described by the controlled hyperchaotic chen dynamics:

$$
\begin{array}{ll}
\dot{\mathrm{y}}_{1}=\mathrm{a}\left(\mathrm{y}_{2}-\mathrm{y}_{1}\right)+\mathrm{u}_{1}, & \dot{\mathrm{y}}_{2}=4 \mathrm{y}_{1}-10 \mathrm{y}_{1} \mathrm{y}_{3}+\mathrm{cy}_{2}+4 \mathrm{y}_{4}+\mathrm{u}_{2} \\
\dot{\mathrm{y}}_{3}=\mathrm{y}_{2}^{2}-\mathrm{by}_{3}+\mathrm{u}_{3}, & \dot{\mathrm{y}}_{4}=-\mathrm{dy}_{1}+\mathrm{u}_{4}
\end{array}
$$

Where $\mathrm{y}_{1}-\mathrm{y}_{4}$ are the states and $\mathrm{u}_{1}-\mathrm{u}_{4}$ are the adaptive controllers to be designed. The hybrid synchronization error is defined as:

$$
\begin{aligned}
& \mathrm{e}_{1}=\mathrm{y}_{1}-\mathrm{x}_{1}, \mathrm{e}_{2}=\mathrm{y}_{2}+\mathrm{x}_{2} \\
& \mathrm{e}_{3}=\mathrm{y}_{3}-\mathrm{x}_{3}, \mathrm{e}_{4}=\mathrm{y}_{4}+\mathrm{x}_{4}
\end{aligned}
$$

A simple calculation gives the error dynamics as:

$$
\begin{aligned}
\dot{\mathrm{e}}_{1}= & \mathrm{a}\left(\mathrm{e}_{2}-\mathrm{e}_{1}-2 \mathrm{x}_{2}\right)+\mathrm{u}_{1} \\
\dot{\mathrm{e}}_{2}= & 4\left(\mathrm{e}_{1}+2 \mathrm{x}_{1}\right)+\mathrm{ce}_{2}+4 \mathrm{e}_{4}- \\
& 10 \mathrm{y}_{1} \mathrm{y}_{3}-10 \mathrm{x}_{1} \mathrm{x}_{3}+\mathrm{u}_{2} \\
\dot{\mathrm{e}}_{3}= & -\mathrm{be}_{3}+\mathrm{y}_{2}^{2}-\mathrm{x}_{2}^{2}+\mathrm{u}_{3} \\
\dot{\mathrm{e}}_{4}= & -\mathrm{d}\left(\mathrm{e}_{1}+2 \mathrm{x}_{1}\right)+\mathrm{u}_{4}
\end{aligned}
$$


Let us define the adaptive functions $\mathrm{u}_{1}(\mathrm{t})-\mathrm{u}_{4}(\mathrm{t})$ as:

$$
\begin{aligned}
\mathrm{u}_{1}(\mathrm{t})= & -\hat{\mathrm{a}}\left(\mathrm{e}_{2}-\mathrm{e}_{1}-2 \mathrm{x}_{2}\right)-\mathrm{k}_{1} \mathrm{e}_{1} \\
\mathrm{u}_{2}(\mathrm{t})= & -4\left(\mathrm{e}_{1}+2 \mathrm{x}_{1}\right)-\hat{c} \mathrm{e}_{2}-4 \mathrm{e}_{4}+ \\
& 10 \mathrm{y}_{1} \mathrm{y}_{3}+10 \mathrm{x}_{1} \mathrm{x}_{3}-\mathrm{k}_{2} \mathrm{e}_{2} \\
\mathrm{u}_{3}(\mathrm{t})= & \hat{\mathrm{be}} \mathrm{e}_{3}-\mathrm{y}_{2}^{2}+\mathrm{x}_{2}^{2}-\mathrm{k}_{3} \mathrm{e}_{3} \\
\mathrm{u}_{4}(\mathrm{t})= & \hat{\mathrm{d}}\left(\mathrm{e}_{1}+2 \mathrm{x}_{1}\right)-\mathrm{k}_{4} \mathrm{e}_{4}
\end{aligned}
$$

Where $\hat{a}-\hat{d}$ are estimates of a-d, respectively and $k_{i}$, $(i=1,2,3,4)$ are positive constants. Substituting Eq. 20 into Eq. 19, the error dynamics simplifies to:

$$
\begin{aligned}
& \dot{e}_{1}=(a-\hat{a})\left(e_{2}-e_{1}-2 x_{2}\right)-k_{1} e_{1} \\
& \dot{e}_{2}=(c-\hat{c}) e_{2}-k_{2} e_{2} \\
& \dot{e}_{3}=-(b-\hat{b}) e_{3}-k_{3} e_{3} \\
& \dot{e}_{4}=-(d-\hat{d})\left(e_{1}+2 x_{1}\right)-k_{4} e_{4}
\end{aligned}
$$

Let us now define the parameter estimation error as:

$$
\begin{aligned}
& e_{a}=a-\hat{a}, e_{b}=b-\hat{b} \\
& e_{c}=c-\hat{c}, e_{d}=d-\hat{d}
\end{aligned}
$$

Substituting Eq. 22 into Eq. 21, researchers obtain the error dynamics as:

$$
\begin{aligned}
& \dot{e}_{1}=e_{a}\left(e_{2}-e_{1}-2 x_{2}\right)-k_{1} e_{1} \\
& \dot{e}_{2}=e_{c} e_{2}-k_{2} e_{2} \\
& \dot{e}_{3}=-e_{b} e_{3}-k_{3} e_{3} \\
& \dot{e}_{4}=-e_{d}\left(e_{1}+2 x_{1}\right)-k_{4} e_{4}
\end{aligned}
$$

For the derivation of the update law for adjusting the estimates of the parameters, the Lyapunov Approach is used. Researchers consider the quadratic Lyapunov function defined by:

$$
\mathrm{V}=\frac{1}{2}\left(\mathrm{e}_{1}^{2}+\mathrm{e}_{2}^{2}+\mathrm{e}_{3}^{2}+\mathrm{e}_{4}^{2}+\mathrm{e}_{\mathrm{a}}^{2}+\mathrm{e}_{\mathrm{b}}^{2}+\mathrm{e}_{\mathrm{c}}^{2}+\mathrm{e}_{\mathrm{d}}^{2}\right)
$$

which is a positive definite function on $\mathrm{R}^{8}$. Researchers also note that:

$$
\begin{aligned}
& \dot{\mathrm{e}}_{\mathrm{a}}=-\dot{\hat{\mathrm{a}}}, \dot{\mathrm{e}}_{\mathrm{b}}=-\dot{\hat{\mathrm{b}}} \\
& \dot{\mathrm{e}}_{\mathrm{c}}=-\dot{\hat{\mathrm{c}}}, \dot{\mathrm{e}}_{\mathrm{d}}=-\dot{\hat{\mathrm{d}}}
\end{aligned}
$$

Differentiating Eq. 24 along the trajectories of Eq. 23 and noting Eq. 25, researchers find that:

$$
\begin{aligned}
\dot{\mathrm{V}}= & -\mathrm{k}_{1} \mathrm{e}_{1}^{2}-\mathrm{k}_{2} \mathrm{e}_{2}^{2}-\mathrm{k}_{3} \mathrm{e}_{3}^{2}-\mathrm{k}_{4} \mathrm{e}_{4}^{2}+ \\
& \mathrm{e}_{\mathrm{a}}\left[\mathrm{e}_{1}\left(\mathrm{e}_{2}-\mathrm{e}_{1}-2 \mathrm{x}_{2}\right)-\dot{\hat{\mathrm{a}}}\right]+ \\
& \mathrm{e}_{\mathrm{b}}\left[-\mathrm{e}_{3}^{2}-\hat{\hat{b}}\right]+\mathrm{e}_{\mathrm{c}}\left[\mathrm{e}_{2}^{2}-\dot{\hat{\mathrm{c}}}\right]+ \\
& \mathrm{e}_{\mathrm{d}}\left[-\mathrm{e}_{4}\left(\mathrm{e}_{1}+2 \mathrm{x}_{1}\right)-\dot{\hat{\mathrm{d}}}\right]
\end{aligned}
$$

In view of Eq. 26, the estimated parameters are updated by the following law:

$$
\begin{aligned}
& \dot{\hat{\mathrm{a}}}=\mathrm{e}_{1}\left(\mathrm{e}_{2}-\mathrm{e}_{1}-2 \mathrm{x}_{2}\right)+\mathrm{k}_{5} \mathrm{e}_{\mathrm{a}}, \dot{\hat{\mathrm{b}}}=-\mathrm{e}_{3}^{2}+\mathrm{k}_{6} \mathrm{e}_{\mathrm{b}} \\
& \dot{\hat{\mathrm{c}}}=\mathrm{e}_{2}^{2}+\mathrm{k}_{7} \mathrm{e}_{\mathrm{c}}, \dot{\hat{\mathrm{d}}}=-\mathrm{e}_{4}\left(\mathrm{e}_{1}+2 \mathrm{x}_{1}\right)+\mathrm{k}_{8} \mathrm{e}_{\mathrm{d}}
\end{aligned}
$$

Where $\mathrm{k}_{5}-\mathrm{k}_{8}$ are positive constants.

Theorem 2: The identical Hyperchaotic Chen Systems (16) and (17) with unknown parameters are globally and exponentially hybrid-synchronized by the adaptive control law (20) where the update law for the parameter estimates a-d is given by Eq. 27 and $\mathrm{k}_{\mathrm{i}}(\mathrm{i}=1,2, \ldots, 8)$ are positive constants. The errors for parameter estimates $e_{a}-e_{d}$ decay to zero exponentially as $t \rightarrow \infty$.

Proof: This result is a simple consequence of the Lyapunov Stability Theory. Researchers know that $\mathrm{V}$ as defined in Eq. 24 is a positive definite function on $\mathrm{R}^{8}$. Substituting Eq. 27 into Eq. 26, researchers obtain:

$$
\begin{aligned}
\dot{\mathrm{V}}= & -\mathrm{k}_{1} \mathrm{e}_{1}^{2}-\mathrm{k}_{2} \mathrm{e}_{2}^{2}-\mathrm{k}_{3} \mathrm{e}_{3}^{2}-\mathrm{k}_{4} \mathrm{e}_{4}^{2}- \\
& \mathrm{k}_{5} \mathrm{e}_{\sigma}^{2}-\mathrm{k}_{6} \mathrm{e}_{\rho}^{2}-\mathrm{k}_{7} \mathrm{e}_{\beta}^{2}-\mathrm{k}_{8} \mathrm{e}_{\mathrm{r}}^{2}
\end{aligned}
$$

which is a negative definite function on $\mathrm{R}^{8}$. Hence by the Lyapunov Stability Theory (Hahn, 1967), it follows that $e_{1}(t) \rightarrow 0$ as $T \rightarrow \infty$ for $i=1,2,3,4$ and $e_{a} \rightarrow 0, e_{b} \rightarrow 0, e_{c} \rightarrow 0, e_{d} \rightarrow 0$ as $t \rightarrow \infty$, exponentially. This completes the proof.

Numerical results: For the numerical simulations, the 4th-order Runge-Kutta Method with time-step $h=10^{-8}$ is used to solve the two systems of differential Eq. 16 and 17 with the adaptive nonlinear controller (Eq. 20) and update law of estimates (Eq. 27).

Researchers take $\mathrm{k}_{\mathrm{i}}=4$ for $\mathrm{i}=1,2, \ldots, 8$. The parameters of the Hyperchaotic Chen Systems are chosen so that the systems (16) and (17) are hyperchaotic, i.e.,

$$
a=35, b=3, c=21, d=2
$$

The initial values of the parameter estimates are chosen as: 


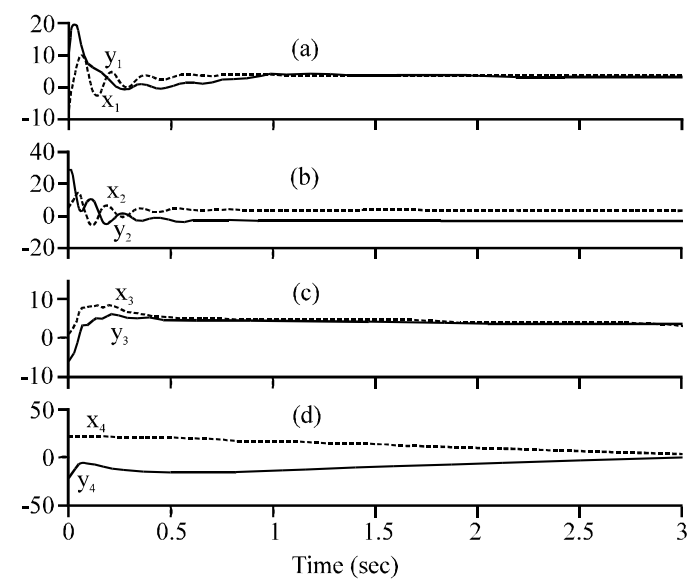

Fig. 7: a-d) Hybrid synchronization of the identical Hyperchaotic Chen Systems

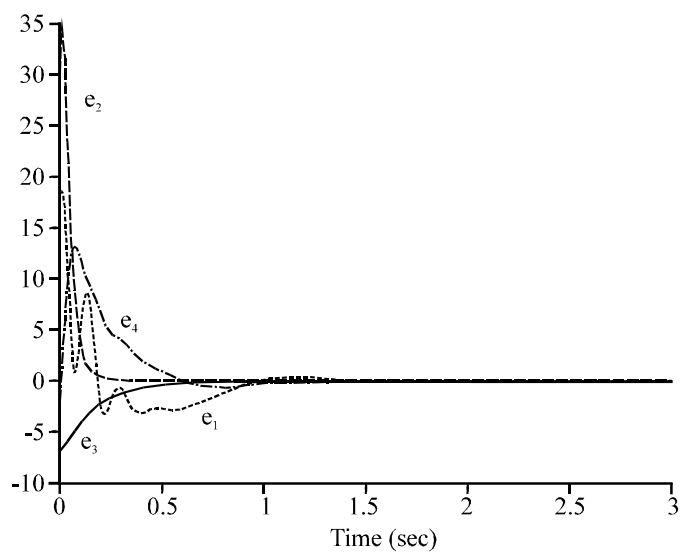

Fig. 8: Time history of the error states $e_{1}-e_{4}$

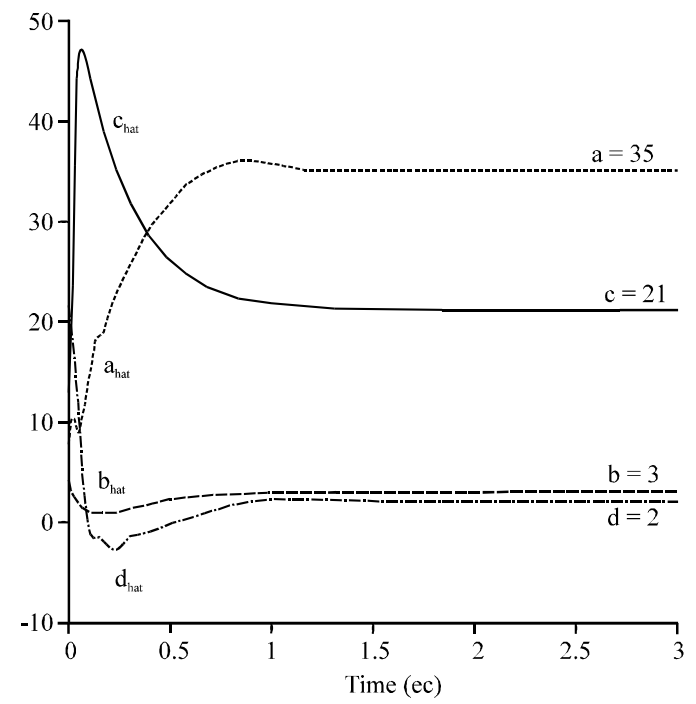

Fig. 9: Time history of the parameter estimates $\hat{a}-\hat{d}$

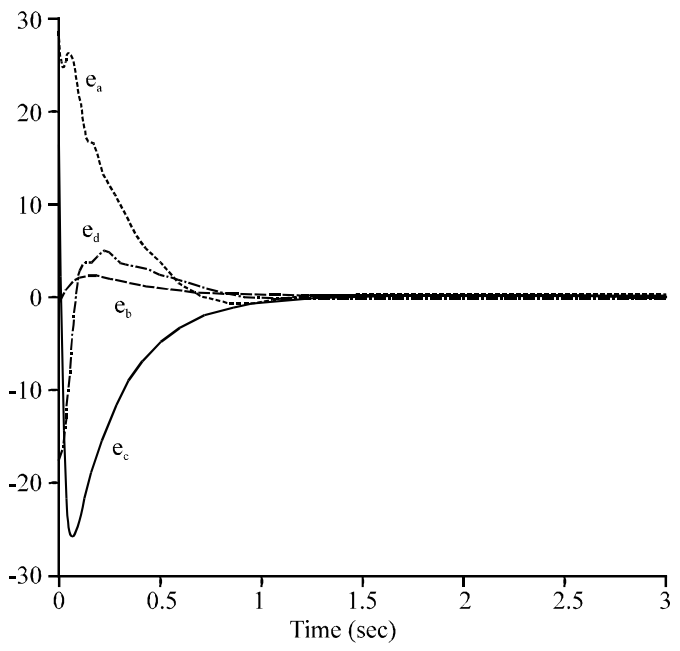

Fig. 10: Time history of the parameter estimation errors

$$
\begin{aligned}
& \mathrm{e}_{\mathrm{a}}-\mathrm{e}_{\mathrm{d}} \\
& \hat{\mathrm{a}}(0)=7, \hat{\mathrm{b}}(0)=4, \hat{\mathrm{c}}(0)=1, \hat{\mathrm{d}}(0)=20
\end{aligned}
$$

The initial values of the master system (16) are chosen as:

$$
x_{1}(0)=-6, x_{2}(0)=17, x_{3}(0)=23, x_{4}(0)=-8
$$

The initial values of the slave system (17) are chosen as:

$$
\mathrm{y}_{1}(0)=12, \mathrm{y}_{2}(0)=17, \mathrm{y}_{3}(0)=-6, \mathrm{x}_{4}(0)=-22
$$

Figure 7 shows the hybrid synchronization of the Hyperchaotic Chen Systems (16) and (17). Figure 8 shows the time-history of the hybrid synchronization errors. Figure 9 shows the time-history of the parameter estimates $\hat{a}-\hat{d}$. Figure 10 shows the time-history of the parameter estimation errors $\mathrm{e}_{\mathrm{a}}-\mathrm{e}_{\mathrm{d}}$.

\section{ADAPTIVE HYBRID SYNCHRONIZATION OF HYPERCHAOTIC LORENZ AND HYPERCHAOTIC CHEN SYSTEMS}

Theoretical results: In this study, researchers derive results for the adaptive hybrid synchronization of non-identical Hyperchaotic Systems viz. Hyperchaotic Lorenz System (Gao et al., 2007) and Chen System (Li-Xin et al., 2010). Thus, the master system is described by the Hyperchaotic Lorenz dynamics:

$$
\begin{aligned}
& \dot{\mathrm{x}}_{1}=\sigma\left(\mathrm{x}_{2}-\mathrm{x}_{1}\right), \dot{\mathrm{x}}_{2}=\rho \mathrm{x}_{1}-\mathrm{x}_{2}-\mathrm{x}_{4}-\mathrm{x}_{1} \mathrm{x}_{3} \\
& \dot{\mathrm{x}}_{3}=\mathrm{x}_{1} \mathrm{x}_{2}-\beta \mathrm{x}_{3}, \dot{\mathrm{x}}_{4}=\operatorname{rx}_{2} \mathrm{x}_{3}
\end{aligned}
$$


Where $\mathrm{x}_{1}-\mathrm{x}_{4}$ are the states and $\sigma, \beta, \rho, \mathrm{r}$ are unknown parameters of the system. The slave system is described by the controlled hyperchaotic chen dynamics:

$$
\begin{aligned}
& \dot{\mathrm{y}}_{1}=\mathrm{a}\left(\mathrm{y}_{2}-\mathrm{y}_{1}\right)+\mathrm{u}_{1} \\
& \dot{\mathrm{y}}_{2}=4 \mathrm{y}_{1}-10 \mathrm{y}_{1} \mathrm{y}_{3}+\mathrm{cy}_{2}+4 \mathrm{y}_{4}+\mathrm{u}_{2} \\
& \dot{\mathrm{y}}_{3}=\mathrm{y}_{2}^{2}-\mathrm{by}_{3}+\mathrm{u}_{3} \\
& \dot{\mathrm{y}}_{4}=-\mathrm{dy}_{1}+\mathrm{u}_{4}
\end{aligned}
$$

Where $\mathrm{y}_{1}-\mathrm{y}_{4}$ are the states, a-d are unknown parameters of the system and $\mathrm{u}_{1}-\mathrm{u}_{4}$ are the adaptive controllers to be designed. The hybrid synchronization error is defined as:

$$
\begin{aligned}
& \mathrm{e}_{1}=\mathrm{y}_{1}-\mathrm{x}_{1}, \mathrm{e}_{2}=\mathrm{y}_{2}+\mathrm{x}_{2} \\
& \mathrm{e}_{3}=\mathrm{y}_{3}-\mathrm{x}_{3}, \mathrm{e}_{4}=\mathrm{y}_{4}+\mathrm{x}_{4}
\end{aligned}
$$

A simple calculation gives the error dynamics as:

$$
\begin{gathered}
\dot{\mathrm{e}}_{1}=\mathrm{a}\left(\mathrm{y}_{2}-\mathrm{y}_{1}\right)-\sigma\left(\mathrm{x}_{2}-\mathrm{x}_{1}\right)+\mathrm{u}_{1} \\
\dot{\mathrm{e}}_{2}=4 \mathrm{y}_{1}-10 \mathrm{y}_{1} \mathrm{y}_{3}+\mathrm{cy}_{2}+4 \mathrm{y}_{4}+ \\
\quad \rho \mathrm{x}_{1}-\mathrm{x}_{2}-\mathrm{x}_{4}-\mathrm{x}_{1} \mathrm{x}_{3}+\mathrm{u}_{2} \\
\dot{\mathrm{e}}_{3}=\mathrm{y}_{2}^{2}-\mathrm{by}_{3}-\mathrm{x}_{1} \mathrm{x}_{2}+\beta \mathrm{x}_{3}+\mathrm{u}_{3} \\
\dot{\mathrm{e}}_{4}=-\mathrm{dy}_{1}+\mathrm{rx}_{2} \mathrm{x}_{3}+\mathrm{u}_{4}
\end{gathered}
$$

Let us define the adaptive functions $\mathrm{u}_{1}(\mathrm{t})-\mathrm{u}_{4}(\mathrm{t})$ as:

$$
\begin{aligned}
& \mathrm{u}_{1}(\mathrm{t})=-\hat{\mathrm{a}}\left(\mathrm{y}_{2}-\mathrm{y}_{1}\right)+\hat{\sigma}\left(\mathrm{x}_{2}-\mathrm{x}_{1}\right)-\mathrm{k}_{1} \mathrm{e}_{1} \\
& \mathrm{u}_{2}(\mathrm{t})=-4 \mathrm{y}_{1}+10 \mathrm{y}_{1} \mathrm{y}_{3}-\hat{c} \mathrm{y}_{2}-4 \mathrm{y}_{4}- \\
& \hat{\rho} \mathrm{x}_{1}+\mathrm{x}_{2}+\mathrm{x}_{4}+\mathrm{x}_{1} \mathrm{x}_{3}-\mathrm{k}_{2} \mathrm{e}_{2} \\
& \mathrm{u}_{3}(\mathrm{t})=-\mathrm{y}_{2}^{2}+\hat{b} \mathrm{y}_{3}+\mathrm{x}_{1} \mathrm{x}_{2}-\hat{\beta} \mathrm{x}_{3}-\mathrm{k}_{3} \mathrm{e}_{3} \\
& \mathrm{u}_{4}(\mathrm{t})=\hat{d} \mathrm{y}_{1}-\hat{\mathrm{r}} \mathrm{x}_{2} \mathrm{x}_{3}-\mathrm{k}_{4} \mathrm{e}_{4}
\end{aligned}
$$

Where $\hat{\sigma}, \hat{\beta}, \hat{\rho}, \hat{r}, \hat{\mathbf{a}}-\hat{\mathrm{d}}$ are estimates of $\sigma, \beta, \rho, \mathrm{r}, \mathrm{a}-\mathrm{d}$, respectively and $\mathrm{k}_{\mathrm{i}}(\mathrm{i}=1,2,3,4)$ are positive constants. Substituting Eq. 33 into Eq. 32, the error dynamics simplifies to:

$$
\begin{aligned}
\dot{e}_{1}= & (a-\hat{a})\left(y_{2}-y_{1}\right)- \\
& (\sigma-\hat{\sigma})\left(x_{2}-x_{1}\right)-k_{1} e_{1} \\
\dot{e}_{2}= & (c-\hat{c}) y_{2}+(\rho-\hat{\rho}) x_{1}-k_{2} e_{2} \\
\dot{e}_{3}= & -(b-\hat{b}) y_{3}+(\beta-\hat{\beta}) x_{3}-k_{3} e_{3} \\
\dot{e}_{4}= & -(d-\hat{d}) y_{1}+(r-\hat{r}) x_{2} x_{3}-k_{4} e_{4}
\end{aligned}
$$

Let us now define the parameter estimation error as:

$$
\begin{aligned}
& e_{a}=a-\hat{a}, e_{b}=b-\hat{b} \\
& e_{c}=c-\hat{c}, e_{d}=d-\hat{d} \\
& e_{\sigma}=\sigma-\hat{\sigma}, e_{\beta}=\beta-\hat{\beta} \\
& e_{\rho}=\rho-\hat{\rho}, e_{r}=r-\hat{r}
\end{aligned}
$$

Substituting Eq. 35 into Eq. 34, researchers obtain the error dynamics as:

$$
\begin{aligned}
& \dot{\mathrm{e}}_{1}=\mathrm{e}_{\mathrm{a}}\left(\mathrm{y}_{2}-\mathrm{y}_{1}\right)-\mathrm{e}_{\sigma}\left(\mathrm{x}_{2}-\mathrm{x}_{1}\right)-\mathrm{k}_{1} \mathrm{e}_{1} \\
& \dot{\mathrm{e}}_{2}=\mathrm{e}_{\mathrm{c}} \mathrm{y}_{2}+\mathrm{e}_{\rho} \mathrm{x}_{1}-\mathrm{k}_{2} \mathrm{e}_{2} \\
& \dot{\mathrm{e}}_{3}=-\mathrm{e}_{\mathrm{b}} \mathrm{y}_{3}+\mathrm{e}_{\beta} \mathrm{x}_{3}-\mathrm{k}_{3} \mathrm{e}_{3} \\
& \dot{\mathrm{e}}_{4}=-\mathrm{e}_{\mathrm{d}} \mathrm{y}_{1}+\mathrm{e}_{\mathrm{r}} \mathrm{x}_{2} \mathrm{x}_{3}-\mathrm{k}_{4} \mathrm{e}_{4}
\end{aligned}
$$

For the derivation of the update law for adjusting the estimates of the parameters, the Lyapunov Approach is used. Researchers consider the quadratic Lyapunov function defined by:

$$
\mathrm{V}=\frac{1}{2}\left(\begin{array}{l}
\mathrm{e}_{1}^{2}+\mathrm{e}_{2}^{2}+\mathrm{e}_{3}^{2}+\mathrm{e}_{4}^{2}+\mathrm{e}_{\mathrm{a}}^{2}+\mathrm{e}_{\mathrm{b}}^{2}+ \\
\mathrm{e}_{\mathrm{c}}^{2}+\mathrm{e}_{\mathrm{d}}^{2}+\mathrm{e}_{\sigma}^{2}+\mathrm{e}_{\beta}^{2}+\mathrm{e}_{\rho}^{2}+\mathrm{e}_{\mathrm{r}}^{2}
\end{array}\right)
$$

Which is a positive definite function on $\mathrm{R}^{12}$. Researchers also note that:

$$
\begin{array}{lll}
\dot{\mathrm{e}}_{\mathrm{a}}=-\dot{\hat{\mathrm{a}}}, & \dot{\mathrm{e}}_{\mathrm{b}}=-\dot{\hat{\mathrm{b}}}, \dot{\mathrm{e}}_{\mathrm{c}}=-\dot{\hat{\mathrm{c}}}, \dot{\mathrm{e}}_{\mathrm{d}}=-\dot{\hat{\mathrm{d}}} \\
\dot{\mathrm{e}}_{\sigma}=-\dot{\hat{\mathrm{O}}}, \dot{\mathrm{e}}_{\beta}=-\dot{\hat{\hat{\beta}}}, \dot{\mathrm{e}}_{\rho}=-\dot{\hat{\hat{\rho}}}, \dot{\mathrm{e}}_{\mathrm{r}}=-\dot{\hat{\mathrm{r}}}
\end{array}
$$

Differentiating Eq. 37 along the trajectories of Eq. 36 and noting Eq. 38, we find that:

$$
\begin{aligned}
\dot{\mathrm{V}}= & -\mathrm{k}_{1} \mathrm{e}_{1}^{2}-\mathrm{k}_{2} \mathrm{e}_{2}^{2}-\mathrm{k}_{3} \mathrm{e}_{3}^{2}-\mathrm{k}_{4} \mathrm{e}_{4}^{2}+ \\
& \mathrm{e}_{\mathrm{a}}\left[\mathrm{e}_{1}\left(\mathrm{y}_{2}-\mathrm{y}_{1}\right)-\dot{\hat{\mathrm{a}}}\right]+\mathrm{e}_{\mathrm{b}}\left[-\mathrm{e}_{3} \mathrm{y}_{3}-\dot{\hat{b}}\right]+ \\
& \mathrm{e}_{\mathrm{c}}\left[\mathrm{e}_{2} \mathrm{y}_{2}-\dot{\hat{\mathrm{c}}}\right]+\mathrm{e}_{\mathrm{d}}\left[-\mathrm{e}_{4} \mathrm{y}_{1}-\dot{\hat{\mathrm{d}}}\right]+ \\
& \mathrm{e}_{\sigma}\left[-\mathrm{e}_{1}\left(\mathrm{x}_{2}-\mathrm{x}_{1}\right)-\dot{\hat{\sigma}}\right]+\mathrm{e}_{\beta}\left[\mathrm{e}_{3} \mathrm{x}_{3}-\dot{\hat{\beta}}\right]+ \\
& \mathrm{e}_{\mathrm{\rho}}\left[\mathrm{e}_{2} \mathrm{x}_{1}-\dot{\hat{\mathrm{c}}}\right]+\mathrm{e}_{\mathrm{r}}\left[\mathrm{e}_{4} \mathrm{x}_{2} \mathrm{x}_{3}-\dot{\hat{\mathrm{r}}}\right]
\end{aligned}
$$

In view of Eq. 39, the estimated parameters are updated by the following law:

$$
\begin{aligned}
& \dot{\hat{\mathrm{a}}}=\mathrm{e}_{1}\left(\mathrm{y}_{2}-\mathrm{y}_{1}\right)+\mathrm{k}_{5} \mathrm{e}_{\mathrm{a}}, \dot{\hat{\mathrm{b}}}=-\mathrm{e}_{3} \mathrm{y}_{3}+\mathrm{k}_{6} \mathrm{e}_{\mathrm{b}} \\
& \dot{\hat{\mathrm{c}}}=\mathrm{e}_{2} \mathrm{y}_{2}+\mathrm{k}_{7} \mathrm{e}_{\mathrm{c}}, \dot{\hat{\mathrm{d}}}=-\mathrm{e}_{4} \mathrm{y}_{1}+\mathrm{k}_{8} \mathrm{e}_{\mathrm{d}} \\
& \dot{\hat{\sigma}}=-\mathrm{e}_{1}\left(\mathrm{x}_{2}-\mathrm{x}_{1}\right)+\mathrm{k}_{9} \mathrm{e}_{\sigma}, \dot{\hat{\hat{\beta}}}=\mathrm{e}_{3} \mathrm{x}_{3}+\mathrm{k}_{10} \mathrm{e}_{\beta} \\
& \dot{\hat{\hat{\rho}}}=\mathrm{e}_{2} \mathrm{x}_{1}+\mathrm{k}_{11} \mathrm{e}_{\rho}, \dot{\hat{\mathrm{r}}}=\mathrm{e}_{4} \mathrm{x}_{2} \mathrm{x}_{3}+\mathrm{k}_{12} \mathrm{e}_{\mathrm{r}}
\end{aligned}
$$


Where, $\mathrm{k}_{\mathrm{i}}(\mathrm{i}=5, \ldots, 12)$ are positive constants.

Theorem 3: The non-identical hyperchaotic Lorenz System (29) and hyperchaotic Chen System (30) with unknown parameters are globally and exponentially hybrid-synchronized by the adaptive control law (33) where the update law for the parameter estimates $\sigma, \beta, \rho$, r, a-d is given by Eq. 40 and $\mathrm{k}_{\mathrm{i}}(\mathrm{i}=1,2, \ldots, 12)$ are positive constants. The errors for parameter estimates $e_{\sigma}, e_{\beta}, e_{\rho}, e_{r}$, $\mathrm{e}_{\mathrm{a}}-\mathrm{e}_{d}$ decay to zero exponentially as $\mathrm{t} \rightarrow \infty$.

Proof: This result is a simple consequence of the Lyapunov Stability Theory. We know that $\mathrm{V}$ as defined in Eq. 37 is a positive definite function on $\mathrm{R}^{12}$. Substituting Eq. 40 into Eq. 39, researcherse obtain:

$$
\begin{gathered}
\dot{\mathrm{V}}=-\mathrm{k}_{1} \mathrm{e}_{1}^{2}-\mathrm{k}_{2} \mathrm{e}_{2}^{2}-\mathrm{k}_{3} \mathrm{e}_{3}^{2}-\mathrm{k}_{4} \mathrm{e}_{4}^{2}-\mathrm{k}_{5} \mathrm{e}_{\mathrm{a}}^{2}-\mathrm{k}_{6} \mathrm{e}_{\mathrm{b}}^{2}- \\
\mathrm{k}_{7} \mathrm{e}_{\mathrm{c}}^{2}-\mathrm{k}_{8} \mathrm{e}_{\mathrm{d}}^{2}-\mathrm{k}_{9} \mathrm{e}_{\sigma}^{2}-\mathrm{k}_{10} \mathrm{e}_{\mathrm{\beta}}^{2}-\mathrm{k}_{11} \mathrm{e}_{\mathrm{\rho}}^{2}-\mathrm{k}_{12} \mathrm{e}_{\mathrm{r}}^{2}
\end{gathered}
$$

Which is a negative definite function on $\mathrm{R}^{12}$. Hence by the Lyapunov Stability Theory (Hahn, 1967), it follows that $e_{1}(t) \rightarrow 0$ as $t \rightarrow 0$ for $i=1,2,3,4$ and all the parameter estimation errors $e_{a}-e_{d}, e_{\sigma}, e_{\beta}, e_{\rho}, e_{r}$ tend to zero exponentially with time. This completes the proof.

Numerical results: For the numerical simulations, the 4th-order Runge-Kutta Method with time-step $\mathrm{h}=10^{-8}$ is used to solve the two systems of differential Eq. 29 and 30 with the adaptive non-linear controller (Eq. 33) and update law of estimates (Eq. 40). Researchers take $\mathrm{k}_{\mathrm{i}}=4$ for $\mathrm{i}=1$, $2, \ldots, 12$. The parameters of the Hyperchaotic Lorenz and Hyperchaotic Chen Systems are chosen so that the systems are hyperchaotic, i.e.,

$$
\begin{gathered}
\sigma=10, \beta=8 / 3, \rho, r=0.1 \\
a=35, b=3, c=21, d=2
\end{gathered}
$$

The initial values of the parameter estimates are chosen as:

$$
\begin{aligned}
& \hat{\mathrm{a}}(0)=1, \quad \hat{\mathrm{b}}(0)=8, \quad \hat{\mathrm{c}}(0)=10, \hat{\mathrm{d}}(0)=7 \\
& \hat{\sigma}(0)=5, \hat{\beta}(0)=14, \hat{\rho}(0)=3, \hat{r}(0)=11
\end{aligned}
$$

The initial values of the master system (16) are chosen as:

$$
x_{1}(0)=2, x_{2}(0)=-5, x_{3}(0)=4, x_{4}(0)=1
$$

The initial values of the slave system (17) are chosen as:

$$
y_{1}(0)=8, y_{2}(0)=-6, y_{3}(0)=-3, y_{4}(0)=-4
$$
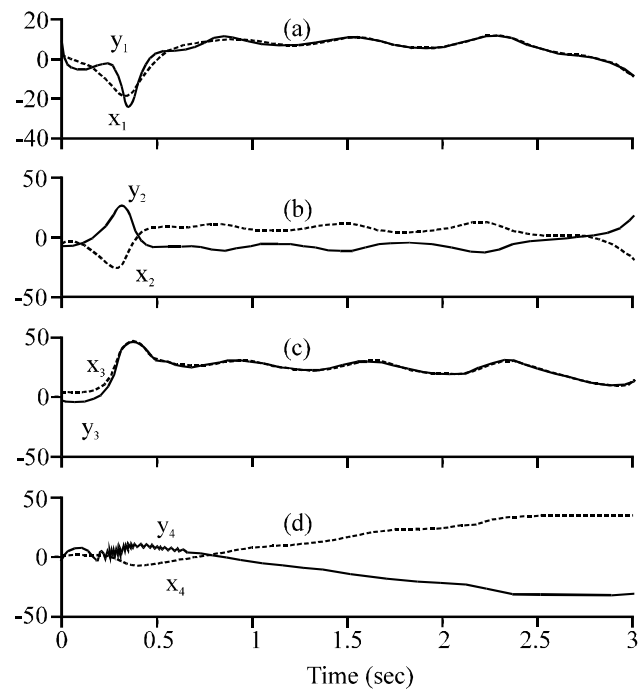

Fig. 11: a-d) Hybrid synchronization of the non-identical Hyperchaotic Lorenz and Chen Systems

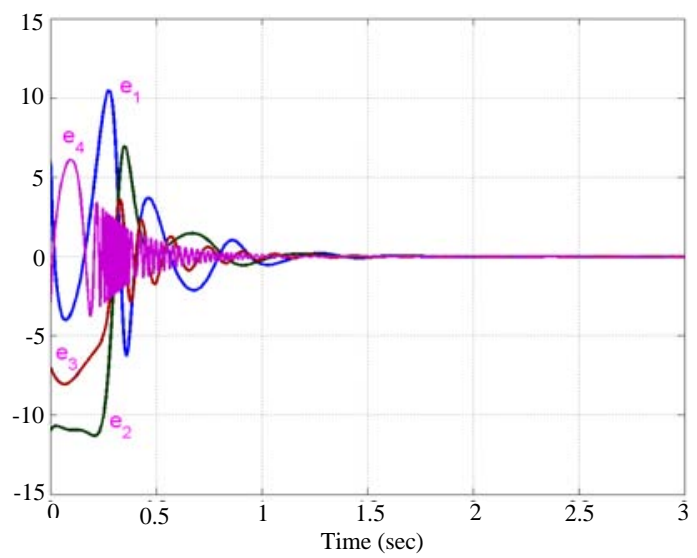

Fig. 12: Time history of the error states $\mathrm{e}_{1}-\mathrm{e}_{4}$

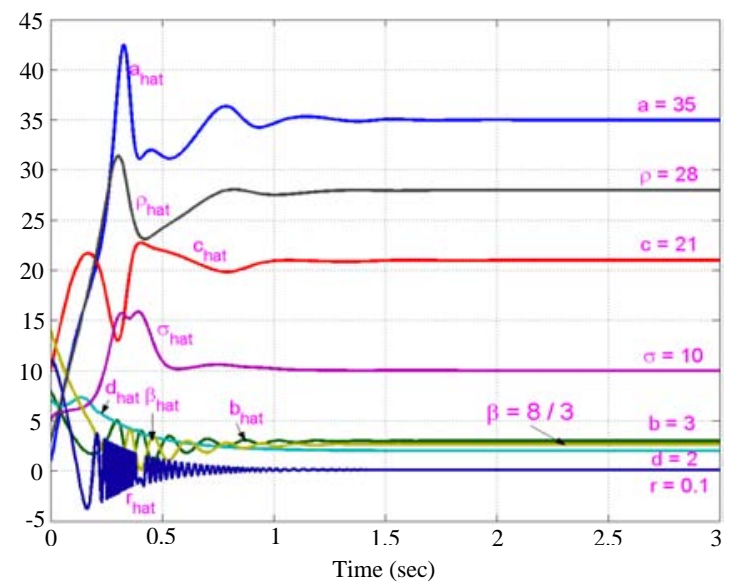

Fig. 13: Time history of the parameter estimates $\hat{a}-\hat{d}, \hat{\sigma}, \hat{\beta}, \hat{\rho}, \hat{r}$ 

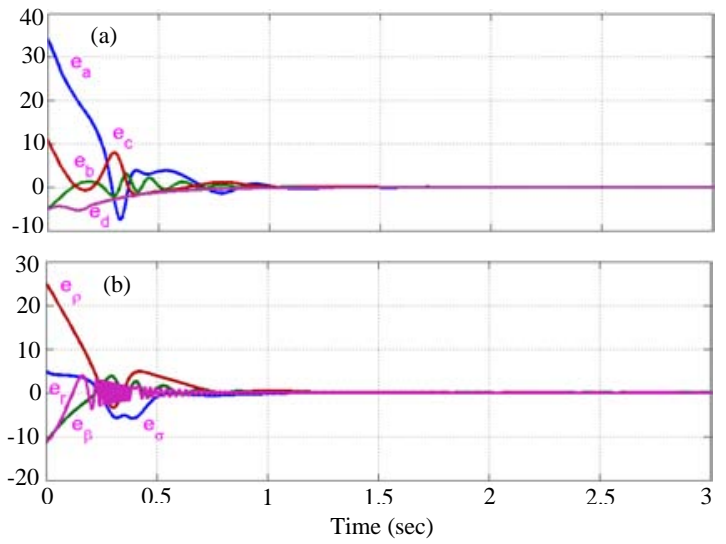

Fig. 14: a, b) Time history of the parameter estimation errors $\mathrm{e}_{\mathrm{a}}-\mathrm{e}_{\mathrm{d}}, \mathrm{e}_{\sigma}, \mathrm{e}_{\beta}, \mathrm{e}_{\rho}, \mathrm{e}_{\mathrm{r}}$

Figure 11 shows the hybrid synchronization of the Hyperchaotic Lorenz and Hyperchaotic Chen Systems (16) and (17). Figure 12 shows the time-history of the hybrid synchronization errors. Figure 13 shows the time-history of the parameter estimates $\hat{a}-\hat{d}, \hat{\sigma}, \hat{\beta}, \hat{\rho}, \hat{r}$. Figure 14 shows the time-history of the parameter estimation errors $\mathrm{e}_{\mathrm{a}}-\mathrm{e}_{\mathrm{d}}, \mathrm{e}_{\sigma}, \mathrm{e}_{\beta}, \mathrm{e}_{\rho}$ and $\mathrm{e}_{\mathrm{r}}$.

\section{CONCLUSION}

In this study, researchers have deployed Adaptive Control Method for achieving adaptive hybrid synchronization of the identical Hyperchaotic Lorenz Systems, the identical Hyperchaotic Chen Systems and non-identical Hyperchaotic Lorenz and Hyperchaotic Chen Systems when the parameters of the systems are unknown. The adaptive hybrid synchronization results derived have been proved using the Lyapunov Stability Theory. Since, the Lyapunov exponents are not required for these calculations, the proposed Adaptive Control Method is very effective and convenient for achieving hybrid synchronization of the hyperchaotic systems addressed in this study. Numerical simulations are shown to demonstrate the effectiveness of the hybrid synchronization results for the hyperchaotic systems discussed in this study.

\section{REFERENCES}

Alligood, K.T., T. Sauer and J.A. Yorke, 1997. An Introduction to Dynamical Systems. Springer, New York, USA.

Blasius, B., A. Huppert and L. Stone, 1999. Complex dynamics and phase synchronization in spatially extended ecological system. Nature, 399: 354-359.
Chen, S. and J. Lu, 2002. Synchronization of an uncertain unified system via adaptive control. Chaos Solitons Fractals, 14: 643-647.

Chiang, T., J. Lin, T. Liao and J. Yan, 2008. Anti-synchronization of uncertain unified chaotic systems with dead-zone nonlinearity. Nonlinear Anal., 68: 2629-2637.

Cuomo, K.M., A.V. Oppenheim and S.H. Strogatz, 1993. Synchronization of lorenz-based chaotic circuits with applications to communications. IEEE Trans. Circuits Syst. II-Analog Digital Signal Process., 40: 626-633.

Gao, T., G. Chen, Z. Chen and S. Cang, 2007. The generation and circuit implementation of a new hyperchaos based upon Lorenz system. Phys. Lett. A, 361: 78-86

Ge, Z.M. and C.C. Chen, 2004. Phase synchronization of coupled chaotic multiple time scales systems. Chaos Solitons Fractals, 20: 639-647.

Hahn, W., 1967. The Stability of Motion. Springer, New York, USA., Pages: 446.

Han, S.K., C. Kerrer and Y. Kuramoto, 1995. D-phasing and bursting in coupled neural oscillators. Phys. Rev. Lett., 75: 3190-3193.

Ho, M.C. and Y.C. Hung, 2002. Synchronization of two different chaotic systems using generalized active control. Phys. Lett. A, 301: 424-428.

Hua, C. and X. Guan, 2003. Robust control of time-delay chaotic systems. Phys. Lett. A, 314: 72-80.

Jia, L. and H. Tang, 2009. Adaptive control and synchronization of a four-dimensional energy resources system of Jiangsu province. Int. J. Nonlinear Sci., 7: 307-311.

Jia, Q., 2007. Projective synchronization of a new hyperchaotic lorenz system. Phys. Lett. A, 370: 40-45.

Kocarev, L. and U. Parlitz, 1995. General approach for chaotic synchronization with application to communication. Phys. Rev. Lett., 74: 5028-5031.

Lakshmanan, M. and K. Murali, 1996. Chaos in Nonlinear Oscillators: Controlling and Synchronization. World Scientific, Singapore.

Li, R.H., W. Xu and S. Li, 2007. Adaptive generalized projective synchronization in different chaotic systems based on parameter identification. Phys. Lett. A., 367: 199-206.

Li-Xin, J., D. Hao and H. Meng, 2010. A new fourdimensional hyperchaotic Chen system and its generalized synchronization. Chinese Phys. B, 19: 501-517.

Lorenz, E.N., 1963. Deterministic nonperiodic flow. J. Atmos. Sci., 20: 130-141.

Mascolo, S. and G. Grassi, 1999. Controlling chaotic dynamics using backstepping design with application to the Lorenz system and Chua's circuit. Int. J. Bifurcation Chaos, 9: 1425-1434. 
Ott, E., C. Grebogi and J.A. Yorke, 1990. Controlling chaos. Phys. Rev. Lett., 64: 1196-1199.

Park, J.H. and O.M. Kwon, 2003. A novel criterion for delayed feedback control of time-delay chaotic systems. Chaos Solitons Fractals, 17: 709-716.

Pecora, L.M. and T.L. Carroll, 1990. Synchronization in chaotic systems. Phys. Rev. Lett., 64: 821-824.

Rossler, O.E., 1979. An equation for hyperchaos. Phys. Lett. A, 71: 155-157.

Sarasu, P. and V. Sundarapandian, 2011. Active controller design for generalized projective synchronization of four-scroll chaotic systems. Int. J. Syst. Signal Control Engin. Appli., 4: 26-33.

Slotine, J.E. and S.S. Sastry, 1983. Tracking control of non-linear systems using sliding surface with application to robotic manipulators. Int. J. Control, 38: 465-492.

Sundarapandian, V. and S. Sivaperumal, 2011a. Anti-synchronization of hyperchaotic Lorenz systems by sliding mode control Int. J. Comput. Sci. Eng., 3: 2450-2457.

Sundarapandian, V. and S. Sivaperumal, 2011b. Global chaos synchronization of the hyperchaotic Qi systems by sliding mode control. Int. J. Comput. Sci. Eng., 3: 2430-2437.

Sundarapandian, V., 2011a. Adaptive control and synchronization of the Shaw chaotic system. Int. J. Found. Comput. Sci. Technol., 1: 1-11.

Sundarapandian, V., 2011b. Adaptive synchronization of uncertain Sprott $\mathrm{H}$ and I chaotic systems. Int. J. Comput. Info. Sys., 2: 1-7.

Sundarapandian, V., 2011c. Anti-synchronization of Arneodo and Coullet systems by active nonlinear control. Int. J. Control Theory Applied, 4: 25-36.

Sundarapandian, V., 2011d. Global chaos synchronization of Shimizu-Morioka and Liu-Chen chaotic systems by active nonlinear control. Int. J. Adv. Sci. Technol., 2: $11-20$.

Sundarapandian, V., 2011e. Global chaos synchronization of liu and harb chaotic systems by active nonlinear control. Int. J. Comput. Inf. Syst., 1: 8-12.
Sundarapandian, V., 2011f. Global chaos synchronization of the Pehlivan systems by sliding mode control. Int. J. Comput. Sci. Eng., 3: 2163-2169.

Sundarapandian, V., 2011g. Hybrid synchronization of Lorenz and Pehlivan chaotic systems by active nonlinear control. Int. J. Adv. Sci. Technol., 2: 10-20.

Sundarapandian, V., 2011h. Hybrid synchronization of hyperchaotic Rossler and hyperchaotic Lorenz systems by active nonlinear control. Int. J. Adv. Sci. Technol., 2: 1-10.

Tan, X., J. Zhang and Y. Yang, 2003. Synchronizing chaotic systems using backstepping design. Chaos Solitons Fractals, 16: 37-45.

Tian, L. J. Xu and M. Sun, 2007. Chaos synchronization of the energy resource chaotic system with active control. Int. J. Nonlinear Sci., 3: 228-234.

Utkin, V.I., 1977. Variable structure systems using sliding mode. IEEE Trans. Autom. Control, 22: 212-222.

Wang, Y.W. and Z.H. Guan, 2006. Generalized synchronization of continuous chaotic systems. Chaos Solitons Fractals, 27: 97-101.

Yan, J.P. and C.P. Li, 2006. Generalized projective synchronization for the chaotic lorenz system and the chaotic chen system. J. Shanghai Univ., 10: 299-304.

Yang, T. and L.O. Chua, 1999. Control of chaos using sampled-data feedback control. Int. J. Bifurcation Chaos, 9: 215-219.

Yassen, M.T., 2003. Adaptive control and synchronization of a modified Chua's system. Applied Math. Comput., 135: 113-128.

Yassen, M.T., 2005. Chaos synchronization between two different chaotic systems using active control. Chaos Solitons Fractals, 23: 131-140.

Zhang, H., X. Ma, M. Li and J. Zou, 2005. Controlling and tracking hyperchaotic Rossler system via active backstepping design. Chaos, Solitons Fractals, 26: 353-361.

Zhang, $\mathrm{X}$. and $\mathrm{H}$. Zhu, 2008. Anti-synchronization of two different hyperchaotic systems via active and adaptive control. Int. J. Nonlinear Sci., 6: 216-223. 